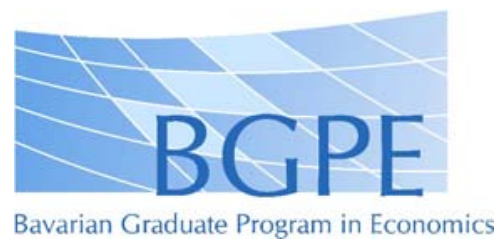

BGPE Discussion Paper

No. 66

\title{
Government R\&D Subsidies as a Signal for Private Investors
}

\author{
Robin Kleer
}

November 2008

\section{ISSN 1863-5733}

Editor: Prof. Regina T. Riphahn, Ph.D.

Friedrich-Alexander-University Erlangen-Nuremberg

(c) Robin Kleer 


\title{
Government R\&D Subsidies as a Signal for Private Investors*
}

\author{
Robin Kleer ${ }^{\dagger}$ \\ University of Würzburg
}

November 12, 2008

Preliminary Version

\begin{abstract}
Government subsidies for $R \& D$ are intended to promote projects with high returns to society but too little private returns to be beneficial for private investors. This may be caused by spillovers or a low appropriability rate. Apart from the direct funding of these projects, government grants may serve as a signal for good investments for private investors. We use a simple signaling model with different types of $R \& D$ projects to capture this phenomenon. In a setup where the subsidy can only be used to distinguish between high and low risk projects, government agency's signal is not very helpful for banks. However, if the subsidy is accompanied by a quality signal, it can lead to increased or better selected private investments.
\end{abstract}

Keywords: Subsidies, Innovation, Asymmetric Information, Signaling

JEL Classification: D82, G28, H20, 033, O38,

${ }^{*}$ I am grateful to Norbert Schulz for continuous guidance, encouragement, and assistance. I would also like to thank Peter Welzel for very helpful comments.

${ }^{\dagger}$ University of Würzburg, Industrial Economics (chair: Norbert Schulz) and Bavarian Graduate Program in Economics, Sanderring 2, 97070 Würzburg, Germany. Phone: +49 (0) 931 - 31-2957, e-mail: robin.kleer@uni-wuerzburg, web: www.vwl.uni-wuerzburg.de/vwl3. 


\section{Introduction}

Government subsidies for R\&D are intended to promote projects with high returns to society but too little private returns to be beneficial for private investors. This may be caused by spillovers of ideas to competitors or a low appropriability rate. Especially basic research is affected by this issue. Most public R\&D policies are justified by this stylized fact. R\&D subsidies are an important tool to support technology policy in OECD countries. In 2005 roughly one third of funds for R\&D are provided by the government (EU 27: 34.7\%, US: 30.4\%, source: IW (2008)).

A difficult problem for government agencies is, however, to identify projects which are beneficial for society but need additional funds to be executed as private returns are too low. If an $R \& D$ project is publicly funded, there is a certain risk that private investment is simply replaced. In economic literature this crowding out effect is widely discussed and the evidence is mixed. David, Hall, and Toole (2000) survey the empirical literature and find that results are dependent on the aggregation level. For a low level of aggregation the proportion of studies reporting a crowding out effect is significantly higher. Lichtenberg $(1984,1987)$ claims that it is difficult to find a valid control group and in several earlier studies a selection bias led to an overestimation of the positive effect of government funded R\&D. Klette, Møen, and Griliches (2000) and Lerner (1999) argue that also political influence and distorted incentives for decision makers may lead to subsidies for the "wrong" R\&D projects.

While the empirical literature on the impact of R\&D subsidies on firms' innovation incentives is growing, theoretical papers are scarce. In a seminal paper, Spence (1984) analyzes firms' incentives to invest in oligopolies when spillovers are present. He shows that without subsidies social welfare eventually decreases as the number of firms increases. This result is driven by the interaction of three simultaneously occurring market failures. First, as $R \& D$ expenditures are to a large extend fixed costs, markets are likely to be concentrated and thus imperfectly competitive, leading to allocative inefficiencies. Second, free riding on rivals' $R \& D$ creates an incentive problem for firms. Finally, if firms use a similar approach to reduce costs, there is a wasteful duplication of $R \& D$ efforts. If the number of firms increases, the positive effect on allocative efficiency gets smaller while the negative incentive and duplication of R\&D efforts effect is still present. Hence, the optimal number of firms is finite 1 Spence shows that in a market with sufficient spillovers it is more efficient to overcome the incentive problem by subsidizing firm's $R \& D$ than by allowing for $R \& D$ cooperations.

Romano (1989) analyzes optimal subsidization in research markets depending on the length of patent life, the character of innovation competition, and the extent of excess burdens associated with the generation of funds for subsidies. He shows that if there is a monopoly in the research market, the optimal subsidy is always positive, independent

\footnotetext{
${ }^{1}$ In fact, depending on parameter combinations this number is small.
} 
of the patent life and the amount of the excess burden 2 In contrast, in a competitive research market, the optimal subsidy is zero for a "long" patent life or a "high" excess burden.

Hinloopen $(1997,2000)$ studies how the effect of R\&D subsidies depends on the degree of cooperation of firms. He introduces taxes that are used to provide firms with R\&D subsides into d'Aspremont and Jacquemin's (1988) model. He shows that this policy can increase private R\&D investments, output, and social welfare. Further, he shows that subsidizing noncooperative $R \& D$ is more effective in raising private $R \& D$ efforts than permitting RJVs or R\&D cartels and in most cases also more effective than permitting RJV cartels 3

This paper addresses an additional effect of subsidies. Apart from the direct funding of these projects, government grants may serve as a signal for good investments to private investors.

Lerner (1999) analyzes the SBIR program (initiated in 1982) that was intended to stimulate innovation in small high tech firms. The study evaluates the performance of firms receiving SBIR rewards in the period of 1983 to 1985. SBIR awardees grew significantly faster in terms of sales and employment compared to similar non-supported firms, from 1985 to 1995 . He attributes capital market imperfections, specifically the difficulty to raise capital for uncertain $R \& D$ projects due to information asymmetries as a source of difference in performance. The SBIR program could play an important role in certifying firms' quality and technological merits of the firms' projects, thereby alleviating capital market imperfections. In line with this interpretation is the importance of the first award compared to subsequent ones. Lerner assumes that this signal to investors is particularly important in high tech industries where it is difficult for smaller banks to analyze risk and potential benefits of research projects. Also, a recently released report of the National Governors Association (NGA) claims that "an SBIR award provides a signal to angel investors that these technologies hold promise and an opportunity to leverage their investments with another source of early-stage funding" (NGA (2008), p.7).

A more recent empirical analysis of Meuleman and de Maeseneire (2008) confirms Lerner's conclusion. In a study of Belgian small and medium sized firms' access to external financing, they find a positive certification effect of obtaining an R\&D grant. Furthermore, the certification effect is stronger for start-up firms. Thus, again, when projects are difficult to evaluate, as in high technology industries or new markets, the $\mathrm{R} \& \mathrm{D}$ grant is more important to secure private funding.

In an interview study of firms that applied to the 1998 US Advanced Technology Program, Feldman and Kelley (2006) find that receipt of a government R\&D subsidy

\footnotetext{
${ }^{2}$ The additional costs to generate funds for the subsidy are called "excess burden" in Romano's model.

${ }^{3}$ Hinloopen uses the Kamien, Muller, and Zang (1992) differentiation for types of R\&D cooperatives.
} 
increased the external funding possibilities. These private funds are important, especially for small- and medium-sized firms.

A survey of possible underinvestment in $R \& D$ caused by capital market imperfections is given in Hall (2002). Generally, she finds that a problem for private investment in research is that there is no capitalized value for R\&D in a firm's balance sheet. Asymmetric information between borrowers and lenders may then cause potential lenders to be reluctant to fund $R \& D$ due to its inherent risk, even if the borrower promised high expected returns. Even venture capitalists, specialized in providing risky capital may fail to provide a solution to capital constraints in R\&D. First, only a small number of firms in specific sectors receive funds. More importantly, as argued in Bhattacharya and Ritter (1983) or Ueda (2004), the threat of expropriation may limit screening activities. If the firm has to reveal valuable private information about the $R \& D$ projects to a private investor to get funds, there is a certain risk that the financier will steal the information.

Our paper is related to the theoretical literature on entrepreneurial finance $4^{4}$ Repullo and Suarez (2000) and Da Rin, Nicodano, and Sembanelli (2006) emphasize the importance of informed financiers, like venture capitalists, to reduce the monitoring or moral hazard problem. In contrast, our model focusses on asymmetric information. Takolo and Tanayama (2008) adapt Holmstrom and Tirole's (1997) framework with financial intermediation in a market where firms are capital constrained to model a signaling effect of R\&D subsidies. In a model with high and low quality entrepreneurs, subsidies reduce capital costs related to the innovation projects and provide a signal to investors. Their model differs in two important ways. First, the focus is on the finance effect of the subsidy. A project without subsidies will never be executed in the considered equilibria. Second, the government agency and private investors prefer the same type of projects, namely high quality projects. In contrast, we model high and low risk projects, where the low risk type is preferred by private investors and the high risk type is preferred by the government agency, imposing conflicting interests between these two actors.

We use a signaling model to capture the problem of asymmetric information between banks, firms, and a government agency. The agency screens R\&D projects and decides on granting a subsidy. Banks observe this signal and then give loans to firms or not. Thus, we assume that firms first seek public funding. However, our results are not altered if we assume that firms first contact private investors who make their funding decisions contingent on the public funding decision. We solve for perfect Bayesian equilibria in two setups. If the subsidy can only be used to distinguish between high and low risk projects, the government agency's signal is not very helpful for banks' investment decision. An equilibrium where the agency is pooling its signal for both project types is very likely. However, if the subsidy is accompanied by a quality signal, it can lead to increased and better selected private investments.

\footnotetext{
${ }^{4}$ For a recent overview of that literature, see Boadway and Keen (2006).
} 
The paper is organized as follows: First, the general signaling model is described. Then, equilibria for both setups are derived. The final section concludes, discusses limitations of our model, and points out interesting topics for further research.

\section{Model}

To show the potential certification character of a government subsidy, a simple signaling model is used. As argued in Czarnitzki and Hussinger (2004) or Czarnitzki and Toole (2006) firms have an incentive to apply for government grants for any project, i.e., not only those where private returns are not sufficient, unless there are significant costs of application. Thus, all projects eligible for subsidies have to be reviewed by the agency 5 For simplification, we assume that there are only two risk classes of projects: High and low risk.

Basic research projects are usually more risky, as the final result is unclear and therefore commercial applications are difficult to foresee. The appropriability level of expenditures for basic research is low (see for example Beise and Stahl (2002)). Furthermore, these projects usually generate high spillovers to competitors. Funk (2002) shows that spillovers from basic research are significantly larger than from developmental research. However, it is necessary for society that these projects are executed as they generate foundations for further research. Thus, we assume that high risk projects are beneficial to society even though they are not privately beneficial. For example, the German Federal Government justifies public R\&D funds where research has long time horizons, a high economic risk and great financial needs. It is argued that this type of research is very likely to be beyond the possibilities of individual companies (BMBF (1993)).

Low risk projects, like improvement of already existing products, are expected to be privately beneficial for companies. Projects of this risk type generate enough private returns to be funded by private investors. On the other hand, social benefits do not exceed investments for this type of projects. Therefore, the agency does not want to grant subsidies for this risk type.

Agency's capital is restricted in a way that it is costly for the agency to subsidize projects. More formally, we assume that the social return function $I(x)$ - which is the agency's objective function - of high and low risk projects is of the following type:

$$
\begin{aligned}
& I_{H}(0)=I_{L}(0)=0, \\
& I_{H}^{\prime}(x)>1,0<I_{L}^{\prime}(x)<1,
\end{aligned}
$$

where $H$ and $L$ indicate high and low risk projects respectively. Projects can be executed with private investment only (social return $I(P)$ ), with subsidies only $(I(S)$ ), or with a combination of private investment and subsidies $(I(S+P))$. We assume that the private investment $P$ is the same for a subsidized and non subsidized projects or in other words

\footnotetext{
${ }^{5}$ In the first setup these are all projects, in the second only those meeting the quality requirement, compare sections 2.1 and 2.2 .
} 
we are not modeling crowding out effects. However, if we allow the private investment to depend on the project being subsidized or not, general results are not altered if we make some reasonable assumptions on the difference between private funding for subsidized and non subsidized projects 6

To model capital market imperfections, we assume that firms do not have funds on their own to perform their R\&D projects but need loans from banks to do so. Asymmetric information in this market is modeled in the way that banks cannot distinguish high and low risk projects. A government agency, due to more experience with similar projects in the past, can. This assumption is in line with the empirical analysis of Lerner (1999) and the modeling of Takolo and Tanayama (2008). Lerner shows that due to more intensive analysis venture capitalists and government agencies perform a significantly better screening and thus have an improved perception of the project's riskiness 7

The agency can use subsidies to promote projects of its interest. Moreover, and that is the focus of the analysis, it can grant subsidies (or not) to signal project types to private investors 8

\subsection{Subsidies without Quality Signal}

Firms apply for subsidies for all of their projects. Therefore, the game structure only shows Nature's random choice of project type. The proportion of high risk projects is $\alpha$, the proportion of low risk projects $1-\alpha$. The agency observes for what type of project the firm is applying and then decides on granting a subsidy $(\mathrm{S})$ or not $(\mathrm{nS})$. Banks observe the agency's decision but not the project type and decide on investing in that project $(\mathrm{L})$ or not $(\mathrm{nL})$. Finally, payoffs are realized. The game structure is shown in figure 1.

Both the agency and banks are assumed to be risk neutral. Expected payoffs are denoted in brackets, agency's on the left, banks' on the right 9 Banks beliefs are $\lambda$ in the no subsidy information set and $\mu$ in the subsidy information set. As explained above, we assume that banks prefer low risk projects. To have a non-trivial decision for banks, we further assume that banks' expected payoffs for high risk projects are negative, while they are positive for low risk projects. If banks do not invest, their payoff is zero 10 Thus,

\footnotetext{
${ }^{6}$ Arguing and calculations are in some cases simply more complex and this way of modeling does not lead to more insights.

${ }^{7}$ Of course, the assumption that banks have no information on the project type and that agency's screening is perfect is for simplification.

${ }^{8}$ The analysis focuses on the asymmetric information problem concerning the project's risk type. We abstract from other information or observation problems, like moral hazard for firms' utilization of investment.

${ }^{9}$ Banks' payoffs are denoted by $A, B, C$, and $D$. Conditions on the relationship between these parameters are established on the following pages.

${ }^{10}$ Note that this formulation is equivalent to assume higher and lower payoffs than payoffs for an outside option for low risk and high risk projects respectively.
} 


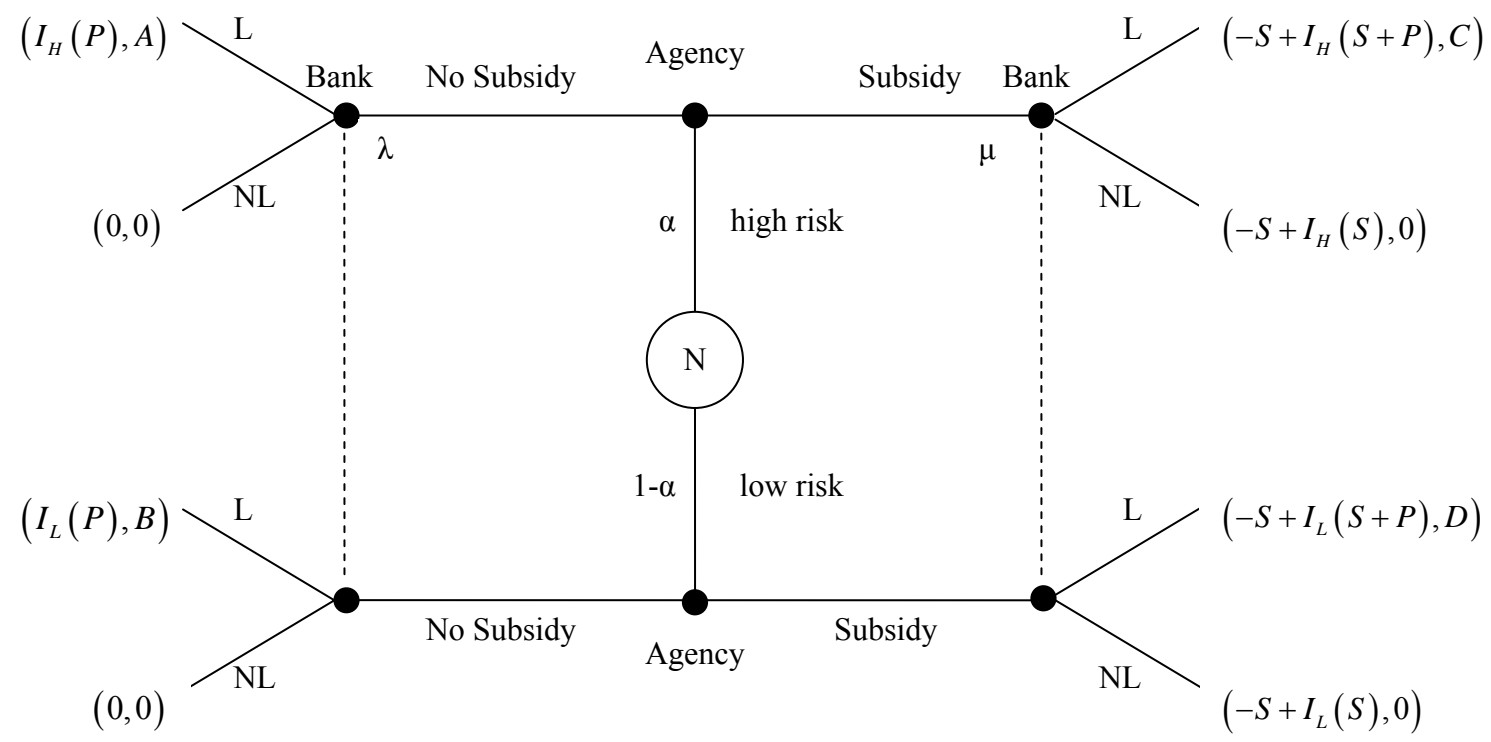

Figure 1: Game structure without quality signal.

the parameters must fulfill the following conditions 11

$$
A<0<B ; \quad C<0<D .
$$

For illustration of strategies, beliefs, and payoffs, assume that a firm is applying for subsidies for a high risk project, the agency decides on giving no subsidies to the project, and banks have the belief $\lambda=0.5$ on the project type and therefore decide to give a loan. Payoffs arising from these strategies are $I_{H}(P)$ for the agency and $A$ for banks.

In the following propositions we identify for what parameter combinations perfect Bayesian equilibria in pure strategies exist. ${ }^{12}$

Proposition 1. There is no separating equilibrium where subsidies are granted for low risk projects and no subsidies are granted for high risk projects.

Proof. See the appendix.

This type of equilibrium would, of course, not be in the interest of the agency anyway and it is pretty intuitive that these strategies can never be an equilibrium. As the strategies clearly indicate the type of project to banks, they will give loans only to their preferred projects, i.e., the low risk ones. Additionally, the agency grants subsidies to the project

\footnotetext{
${ }^{11}$ The investment $P$ is already included in banks' expected payoffs.

${ }^{12}$ We restrict attention to pure strategies for the agency because in that way the agency can define a strict policy and the subsidy decision is not taken randomly. For banks, the decision to give loans or not is based on the expected profit and is therefore - except for the case of equality of both decisions - a pure strategy in equilibrium. We do also only consider equilibria where the equilibrium strategy makes the player strictly better off than the deviation strategy. However, a change of this assumption would not alter our results.
} 
type it does not prefer. Therefore, the agency has a clear incentive to deviate from this strategy since the agency grants subsidies only to its not preferred projects and only these projects receive private funding.

The agency's most preferred equilibrium would be one where subsidies are granted to high risk projects only. However, as the following proposition shows, this equilibrium only exists under very strict assumptions to the social return function.

Proposition 2. A separating equilibrium where subsidies are granted for high risk projects and no subsidies are granted for low risk projects exists only if

$$
I_{H}(P)<-S+I_{H}(S) .
$$

In this equilibrium banks give no loans to subsidized projects and give loans to the non subsidized ones.

Proof. See the appendix.

As before, the signal perfectly reveals project types to banks with the same implication for banks' strategies. In contrast to the candidate equilibrium in proposition 1, the agency at least subsidizes its preferred project type. For the "desired" equilibrium - where the agency only grants subsidies to projects with a high social return and a private return that is too little to guarantee private investment - to exist, the very strict condition (2.1) on the social return function and the amount of subsidy $S$ in comparison to the private investment $P$ must hold. First, the subsidy must be larger than the private investment. Second, the slope of $I_{H}$ must be large between $P$ and $S$ to offset for the agency's investment $S$ in the payoff function. Even if this equilibrium exists, the socially preferred projects then only receive public and no private funding.

In addition to the candidate equilibria considered so far, there is also the possibility that the agency is making no difference between the type of project and thus revealing no information on the riskiness of projects to banks.

\section{Proposition 3.}

a) There is an equilibrium where the agency is pooling on $S$ if

a1) $\alpha \cdot C+(1-\alpha) \cdot D>0$,

a2) $\lambda \cdot A+(1-\lambda) \cdot B<0$, and

a3) $-S+I_{L}(S+P)>0$.

Banks beliefs in this equilibrium are $\mu=\alpha$ and $\lambda>\frac{B}{B-A}$ and they give loans to subsidized projects and no loans to non subsidized projects.

b) There is an equilibrium where the agency is pooling on $n S$ if

b1) $\alpha \cdot A+(1-\alpha) \cdot B>0$,

b2) $\mu \cdot C+(1-\mu) \cdot D<0$, and

bз) $-S+I_{H}(S)<I_{H}(P)$.

Banks' beliefs in this equilibrium are $\lambda=\alpha$ and $\mu>\frac{D}{D-C}$ and they give loans to non subsidized projects and no loans to subsidized projects. 
Proof. See the appendix.

The intuition for the equilibrium pooling on $\mathrm{S}$ is the following. First, banks' expected profits if a project is subsidized must be positive $(a 1)$. Otherwise, banks would not give loans and there would be an incentive to deviate for low risk types. Second, beliefs $\lambda$ off the equilibrium path must be in a way that expected profits for non subsidized projects are negative ( $a 2)$. Again, else there would be an incentive to deviate for low risk types as the agency prefers low risk projects to be solely privately financed instead of being publicly and privately financed. As only subsidized projects get loans, there is clearly no incentive to deviate for high risk projects since subsidizing these projects is in the interest of the agency anyway. Finally, the private investment has to be high enough that the agency prefers the low risk projects to be both publicly and privately financed instead of not being financed at all $(a 3){ }^{13}$

For the equilibrium pooling on $\mathrm{nS}$, the intuition is similar. Expected profits for non subsidized projects must be positive (b1) or else there is an incentive to deviate for high risk projects. Also, beliefs $\mu$ off the equilibrium path must be in a way that expected profits for subsidized projects are negative (b2). Otherwise there is again an incentive to deviate for high risk projects. If these two conditions hold, there is no incentive to deviate for low risk projects as deviating would only result in subsidizing the not preferred project and reducing private investment. For this equilibrium to exist it is again necessary that private investment is large enough. Otherwise the agency would prefer to give subsidies to high risk projects even though that would lead to no private investment for these projects (b3).

In this first setup, the role of the agency is thus not very fulfilling. Only if a very strict condition on the social return function and the amount of subsidy in comparison to the private investment holds, there is a real impact of the agency's strategy on the outcome of the game. In the pooling equilibria the signal has no impact at all. In other words: The mere fact that the agency is able to distinguish between basic and applied research is useless for private investors, if the agency decides not to forward this information.

Thus, for the government agency to play an important role and to have a real (and hopefully positive) impact on innovation investments, there must be another factor when granting subsidies. One factor might be that the agency acts as a filter for low quality projects. In the following section we add this property to the agencies signal.

\subsection{Subsidies with Quality Signal}

The game has the same structure as before, with the exception that only some R\&D projects qualify for subsidies. The idea is that only a proportion $p$ of projects in both risk classes met certain requirements of the agency, like the size of the R\&D laboratory

\footnotetext{
${ }^{13}$ If we require beliefs to be justifiable in the sense of McLennan (1985), the belief $\lambda$ as given in part a) of proposition 3 is not possible and there is no equilibrium where the agency is pooling on S. The proof is given as a remark on proposition 3 in the appendix.
} 
or a minimum number of researchers with a certain experience in the particular field of technology. Projects that fail these pre-screening quality requirements are automatically rejected without any explicit decision from the agency. That is, the agency cannot grant a subsidy to these projects even if it wanted to. These projects are of lower quality than the other projects. As before, banks can neither distinguish between high and low risk nor high and low quality projects. The information subset now contains four nodes with beliefs $\lambda_{1}$ to $\lambda_{4}{ }^{14}$ The changed game structure is shown in figure 2.

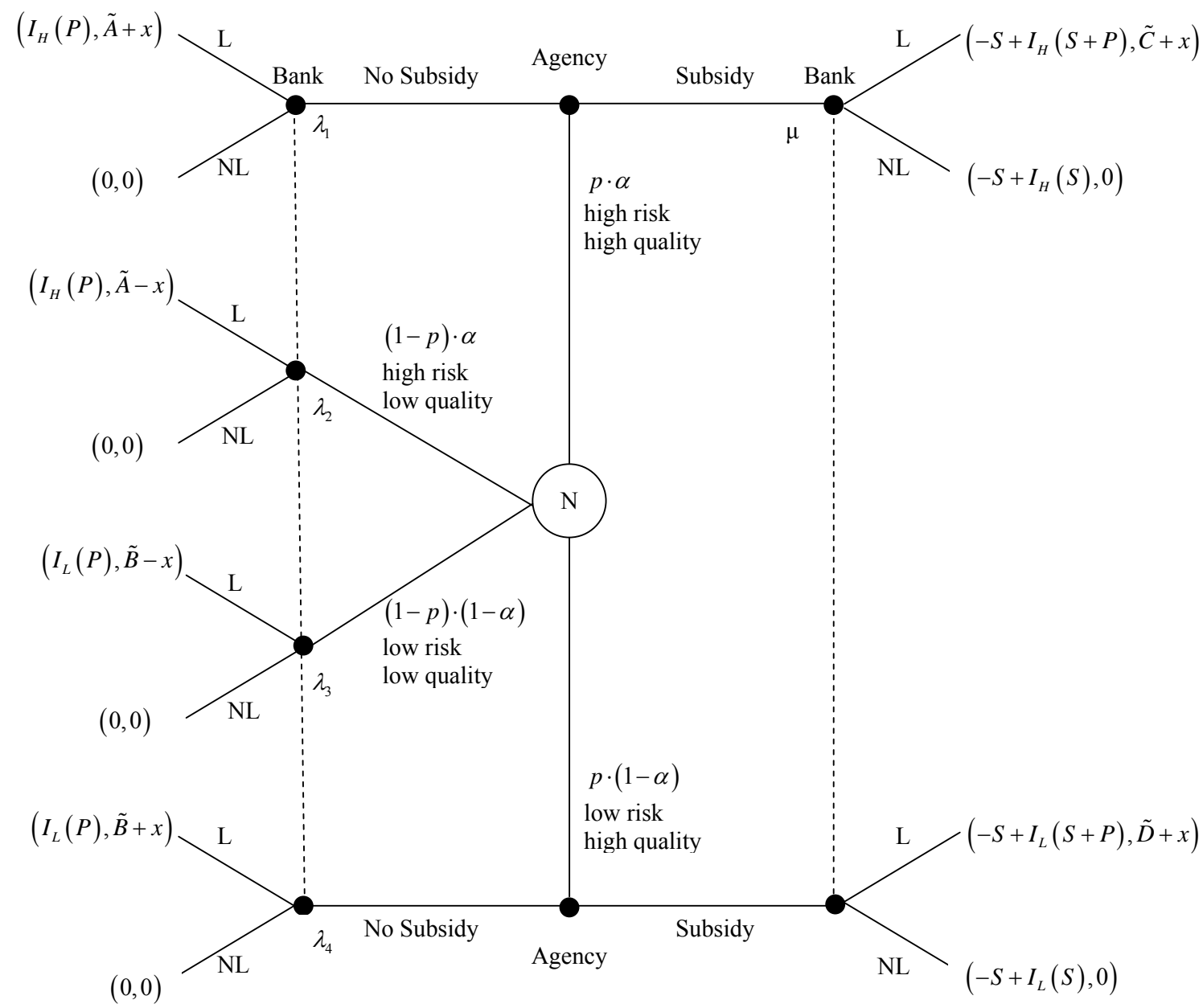

Figure 2: Game Structure with Quality Signal.

We assume that banks' expected payoffs for low quality projects are $2 x$ lower than expected payoffs for high quality projects. To assure comparability of the two setups, ex ante expected payoffs for banks remain unchanged. Banks' expected profit can be split up in two groups for low and high quality projects:

$$
Y=(\tilde{Y}+x) \cdot p+(\tilde{Y}-x) \cdot(1-p)
$$

\footnotetext{
${ }^{14}$ Theoretically, we could also include nodes in the game tree for low quality projects which receive subsidies. However, these nodes cannot be reached as low quality projects cannot receive subsidies. Therefore these nodes are omitted.
} 
where $Y \in\{A, B, C, D\}$. However, depending on the agency's subsidizing strategy banks can update their beliefs and recalculate expected payoffs.

If a project is not subsidized, there are now two possibilities. Either the agency choose not to, or the project did not even qualify to apply for subsidies and is therefore of lower quality. If a project is subsidized on the other hand, banks can be sure it is high quality type. This changes the variety of possible equilibria.

Proposition 4. There is no separating equilibrium where subsidies are granted for low risk projects and no subsidies are granted for high risk projects.

Proof. See the appendix.

The intuition for the non-existence of this type of equilibrium is the same as in the previous setup. Subsidizing clearly indicates low risk projects to banks and hence loans are given to this type of projects. Therefore, the agency has an incentive to deviate for high risk projects.

However, the new property of subsidizing, i.e., the included quality signal, makes conditions for the agency's preferred equilibrium less restrictive.

Proposition 5. There is a separating equilibrium where subsidies are granted for high risk projects and no subsidies are granted for low risk projects if

a) $\tilde{C}+x>0, \lambda_{2} \cdot(\tilde{A}-x)+\lambda_{3} \cdot(\tilde{B}-x)+\lambda_{4} \cdot(\tilde{B}+x)>0$, i.e., loans are given to both types of projects, or

b) $\tilde{C}+x<0$ and $\lambda_{2} \cdot(\tilde{A}-x)+\lambda_{3} \cdot(\tilde{B}-x)+\lambda_{4} \cdot(\tilde{B}+x)<0$, i.e., no loans are given to both types of projects, or

c) $\tilde{C}+x>0, \lambda_{2} \cdot(\tilde{A}-x)+\lambda_{3} \cdot(\tilde{B}-x)+\lambda_{4} \cdot(\tilde{B}+x)<0$ and $-S+I_{L}(S+P)<0$, i.e., loans are given to high risk projects only and the agency prefers low risk projects rather to be not financed than to be financed both privately and publicly, or

d) $\tilde{C}+x<0, \lambda_{2} \cdot(\tilde{A}-x)+\lambda_{3} \cdot(\tilde{B}-x)+\lambda_{4} \cdot(\tilde{B}+x)>0$ and $I_{H}(P)<-S+I_{H}(S)$, i.e., the same condition as in the previous setup: Only low risk projects are privately financed and the agency prefers a solely publicly financed to a solely privately financed high risk project.

In all cases, banks' beliefs are $\lambda_{1}=0, \lambda_{2}=(1-p) \cdot \frac{\alpha}{1-\alpha \cdot p}, \lambda_{3}=(1-p) \cdot \frac{1-\alpha}{1-\alpha \cdot p}, \lambda_{4}=p \cdot \frac{1-\alpha}{1-\alpha \cdot p}$, and $\mu=1$.

Proof. See the appendix.

If a subsidy is a real signal for quality, chances that the agency's (and thus, society's) preferred equilibrium exists are increased. For banks it is important to adjust their beliefs $\lambda_{i}$ if no subsidy is observed, because although we are considering a separating equilibrium, there are still three possibilities for the project type. There are high risk 
projects that did not qualify for subsidies $\left(\lambda_{2}\right)$ and low risk projects which are either of low quality and therefore not subsidized $\left(\lambda_{3}\right)$ or of high quality and the agency chooses not to subsidize $\left(\lambda_{4}\right)$. Banks' belief $\lambda_{2}$ for example must therefore be calculated as the conditional probability of a high risk project, given that the project is not subsidized. Compared to the ex ante situation, the expected payoff is modified in two ways. First, the expected payoff for high risk projects is decreased as all high risk projects are now of low quality. Second, the proportion of low risk type projects - the ones banks prefer - is increased. Therefore, it is not clear whether loans to non subsidized projects in the changed situation are more likely. With beliefs $\lambda_{i}$ and $\mu$ banks calculate expected payoffs and decide to give loans or not. Given these decisions, it is intuitive that the agency has no incentive to deviate in cases $a$ ) and $b$ ). Either both types of project or no type of project are privately funded and the agency thus only chooses to subsidize the projects it prefers, i.e., the high risk type projects. In case $c$ ) the quality restriction makes high risk, high quality projects profitable for private investors. On the other hand, the negative effect of low quality projects is high such that private investors do not want to finance projects that did not meet the agency's quality restriction. An additional condition on the agency's payoff has to hold such that there is no incentive to deviate for low risk projects from the candidate equilibrium. Case $d$ ) is equivalent to the condition in proposition 2 in the previous setup.

The extended setup, with pre-screening quality restrictions, also changes conditions for the pooling equilibria. This is particularly striking for the equilibrium where the agency is pooling on S. Due to the automatically rejected projects the non subsidy information set is still reached on the equilibrium path.

\section{Proposition 6.}

a) There is an equilibrium where the agency is pooling on $S$ if

(a1) $\alpha \cdot(\tilde{C}+x)+(1-\alpha)(\tilde{D}+x)>0$,

(a2) $\alpha \cdot(\tilde{A}-x)+(1-\alpha)(\tilde{B}-x)<0$, and

(аз) $-S+I_{L}(S+P)>0$.

Banks' beliefs in this equilibrium are $\lambda_{1}=\lambda_{4}=0, \lambda_{2}=\alpha, \lambda_{3}=1-\alpha, \mu=\alpha$ and they give loans to subsidized projects and no loans to non subsidized projects.

b) There is an equilibrium where the agency is pooling on $n S$ if

(b1) $\alpha \cdot A+(1-\alpha) \cdot B>0$,

(b2) $\mu \cdot(\tilde{C}+x)+(1-\mu)(\tilde{D}+x)<0$, and

(b3) $-S+I_{H}(S)<I_{H}(P)$.

Banks' beliefs in this equilibrium are $\lambda_{1}=p \cdot \alpha, \lambda_{2}=(1-p) \cdot \alpha, \lambda_{3}=(1-p) \cdot(1-\alpha)$, $\lambda_{4}=p \cdot(1-\alpha)$, and $\mu>\frac{D}{D-C}$ and they give loans to non subsidized projects and no loans to subsidized projects.

Proof. See the appendix. 
Comparing requirements for equilibria in proposition 3 and 6 , we see that the conditions for the equilibrium where the agency is pooling on $\mathrm{S}$ get less strict while they get more restrictive for the $\mathrm{nS}$ pooling equilibrium. Consider first the equilibrium where the agency grants subsidies to both types of projects. The first condition requires the expected profit for the combination of subsidized high and low risk projects to be positive. In proposition 6, however, this expected profit only includes high quality projects. The condition is therefore less restrictive. The problem with the second condition is that in proposition 3 beliefs $\lambda$ can be chosen as high as needed that the condition holds while in proposition $6 \lambda_{2}=\alpha$ is required because the information set is reached in equilibrium 15 The argumentation is therefore only true for $\lambda=\alpha$. In this case the second condition requires that expected profits for the combination of non subsidized high and low risk projects is negative. As in proposition 6 only the low quality projects are included, this condition is less restrictive 16

The opposite is true for the equilibrium where the agency is giving no subsidies to any project. The first and the last condition is the same in both cases. The second condition, however, is more restrictive in proposition 6 as banks know that subsidized projects are of high quality. Therefore, the condition that the expected profit of the combination of high and low risk projects is negative is less likely to hold 17

\section{Conclusion}

This paper analyzes the impact of a government subsidy as a signal to private investors. In our simplified framework it is assumed that firms apply for subsidies for any type of project. In the model's first setup, there are projects of two risk types: High risk projects with little private but high social returns, preferred by the agency and low risk projects with high private but little social returns, preferred by private investors. A government agency screens projects and observes their types. Then the agency decides on granting a subsidy. Banks only observe the agency's decision but not the project type and give loans to projects or not.

In the first formulation, the agency's subsidy gives no quality signal. We show that in this setup an equilibrium where the agency is pooling its strategy for both risk types either on $\mathrm{S}$ or on $\mathrm{nS}$ is very likely. For an equilibrium where the agency is only subsidizing those projects where private returns are not sufficient, a very strict condition on the social return function and the amount of private and public investment must hold.

This changes if there is a pre-screening quality requirement for subsidies. In this setup only a certain proportion of projects meet the agency's quality standard. Only for

\footnotetext{
${ }^{15}$ Since $\lambda_{1}=\lambda_{4}=0, \lambda_{2}$ has to be compared with $\lambda$ and $\lambda_{3}$ with $1-\lambda$.

${ }^{16}$ Another indicator that conditions for the pooling equilibrium on $\mathrm{S}$ get less restrictive is that beliefs in proposition 3 are not justifiable.

${ }^{17}$ In this case, beliefs $\mu$ can be chosen freely for both conditions. However, with the same beliefs the condition in proposition 6 is less likely to hold. Furthermore, if $\tilde{C}+x>0$, there are no beliefs for this condition to hold as $\tilde{D}+x>0$.
} 
these projects the agency is deciding on granting subsidies. It is shown that the agency can now effectively differentiate between project types and thus fulfill its role of being a sponsor for projects that are socially desirable. Conditions for this separating equilibrium are likely to hold. Thus, for the signal to be socially beneficial, it is important that it also reveals quality information on projects.

Lerner's (1999) study generally shows the positive impact of a signaling effect of the subsidy. In the light of our results it would be interesting to redo a similar study that explicitly controls for the contained quality information in the signal.

Our model has several simplifying assumptions. We totally abstract from firms' decisions. This is done because firms have an incentive to apply for subsidies for any type of project in the short run. In the long run, however, firms could adapt their research strategies, depending on agency's and banks' behavior. This would then in turn influence conditions for equilibria.

Projects are restricted to be of two different types and we assume perfect screening by the agency and no screening by banks. A setup where projects differ gradually and agency's screening is just superior to banks' screening would be more realistic, yet not analytically tractable.

Finally, we abstract from other information or observation problems. While it would be interesting to study moral hazard for firms' utilization of investment, this paper restricts attention to the asymmetric information problem, which is definitely of importance for investors in uncertain $\mathrm{R} \& \mathrm{D}$ projects.

Our model confirms the empirical observations of Lerner (1999), Feldman and Kelley (2006), and Meuleman and de Maeseneire (2008): Subsidies can have a signaling character if a government agency is better informed about projects than private investors. However, as we have shown in the second setup, it is crucial that the signal reveals quality information about projects to private investors. 


\section{Appendix}

Proof of Proposition 1. If there was such an equilibrium, banks beliefs must be $\lambda=1$ and $\mu=0$. Therefore, banks decide to give no loan if they observe no subsidy for a project (since $A<0$ ) and give loans if a subsidy is observed (since $D>0$ ). That gives the agency an incentive to deviate if a project is of high risk type, because the payoff when deviating to grant a subsidy $\left(-S+I_{H}(S+P)>0\right)$ is higher than the agency's payoff when sticking to the no subsidy strategy.

Proof of Proposition 2. In the candidate equilibrium, banks beliefs must be $\lambda=0$ and $\mu=1$. Therefore banks decide to give no loan if a subsidy is observed (since $C<0$ ) and give loans if a subsidy is observed (since $B>0$ ). The agency has no incentive to deviate for low risk types as $I_{L}(P)>-S+I_{L}(S)$. For high risk types, agency's payoff is $-S+I_{H}(S)$. If the agency deviates and gives no subsidy to high risk types its payoff changes to $I_{H}(P)$. Thus, there is no incentive to deviate if $-S+I_{H}(S)>I_{H}(P)$.

Proof of Proposition 3. a) If the agency decides on subsidizing both types of project, banks' belief $\mu=\alpha$. Therefore, banks decide to give loans when a subsidy is observed if

$$
\alpha C+(1-\alpha) D>0
$$

Off the equilibrium path, banks give loans if

$$
\lambda A+(1-\lambda) B>0
$$

If both 4.1 and (4.2) hold, there is an incentive to deviate for low risk types since $-S+I_{L}(S+P)<I_{L}(P)$.

If (4.1) holds and 4.2 does not hold, there is an incentive to deviate for low risk types if $-S+I_{L}(S+P)<0$. There is no incentive to deviate for high risk types since $-S+I_{H}(S+P)>0$.

If (4.1) does not hold there is an incentive to deviate for low risk types since $-S+I_{L}(S)<\min \left\{I_{L}(P), 0\right\}=0$.

Thus, there is an equilibrium where the agency is pooling on $\mathrm{S}$ if $\alpha C+(1-\alpha) D>0, \lambda A+(1-\lambda) B<0$ and $-S+I_{L}(S+P)>0$. In this equilibrium the agency always grants a subsidy, banks give no loans if no subsidy is observed and give loans if a subsidy is observed. Banks' beliefs are $\mu=\alpha$ and $\lambda>\frac{B}{B-A}[18$

b) If the agency decides on subsidizing neither type of project banks' belief $\lambda=\alpha$.

Therefore, banks decide to give loans when no subsidy is observed if

$$
\alpha A+(1-\alpha) B>0 .
$$

\footnotetext{
${ }^{18}$ The boundary for belief $\lambda$ is derived from 4.2 not holding.
} 
Off the equilibrium path, banks give loans if

$$
\mu C+(1-\mu) D>0
$$

If 4.3 holds and 4.4 does not hold, there is no incentive to deviate for low risk types since $I_{L}(P)>-S+I_{L}(S)$, and no incentive to deviate for high risk types if $-S+I_{H}(S)<I_{H}(P)$.

If (4.3) and 4.4 hold, there is an incentive to deviate for high risk types since $I_{H}(P)<-S+I_{H}(S+P)$.

If 4.3 does not hold, there is an incentive to deviate for high risk types since $0<\min \left\{-S+I_{H}(S),-S+I_{H}(S+P)\right\}=-S+I_{H}(S)$.

Thus, there is no incentive to deviate from the candidate equilibrium if $(4.3)$ holds, (4.4) does not hold and $-S+I_{H}(S)<I_{H}(P)$. Beliefs in this equilibrium are $\lambda=\alpha$ and $\mu>\frac{D}{D-C} 19$

\section{Remark on proposition 3 a):}

Beliefs $\lambda$ are not justifiable for the following reason: The agency would never deviate for high risk types (no matter what strategy the banks are using when no subsidy is observed) because $-S+I_{H}(S+P)>\max \left\{0, I_{H}(P)\right\}$. For low risk types the deviation would make sense, if a deviation induces banks to give a loan. Hence, banks could infer from agency's payoffs that a deviation from the candidate equilibrium would only make sense if the project is of low risk type. Therefore, banks have to assign zero probability to the node belonging to high risk types, i.e., $\lambda=0$. If the belief is $\lambda=0$, banks would indeed give loans if no subsidy is observed as $B>0$. In this case, the agency has an incentive to deviate for low risk types. Thus, there is no perfect Bayesian equilibrium with justifiable beliefs where the agency is pooling on S.

Proof of Proposition 4. The proof works in a similar way as in the first setup. If a subsidy is observed, banks' belief is still $\mu=0$. Therefore, banks decide to give a loan if a subsidy is observed $(\tilde{D}+x>0)$. However, banks can no longer be sure of the project type if there is no subsidy observed, because it is also possible, that the project did not even qualify for subsidies. So banks have to calculate conditional probabilities for their beliefs $\lambda_{i}$. However, no matter if banks decide to give a loan when no subsidy is observed or not, there is always an incentive to deviate for high risk projects since $-S+I_{H}(S+P)>\max \left\{I_{H}(P), 0\right\}=I_{H}(P)$.

\footnotetext{
${ }^{19}$ The boundary for belief $\mu$ is derived from 4.4 not holding.
} 
Proof of Proposition 5. In the proposed equilibrium the agency grants a subsidy for all high risk projects that qualify and grants no subsidy for low risk projects. Thus, if no subsidy is observed, a project is either low risk type, or high risk type and low quality. Banks can therefore update beliefs $\lambda_{i}$. Belief $\lambda_{1}=0$ since high risk projects of high quality receive a subsidy. The probability that a project is non subsidized is

$$
\operatorname{prob}(\text { non subsidized })=\underbrace{(1-p) \cdot \alpha}_{\text {prob (high risk } \wedge \text { low quality })}+\underbrace{(1-\alpha)}_{\text {prob(low risk })} .
$$

Therefore

$$
\lambda_{2}=\operatorname{prob}(\text { high risk } \mid \text { non subsidized })=\frac{(1-p) \cdot \alpha}{(1-p) \cdot \alpha+(1-\alpha)}=\frac{(1-p) \cdot \alpha}{1-\alpha \cdot p},
$$

and

$$
\lambda_{3}+\lambda 4=\operatorname{prob}(\text { low risk } \mid \text { non subsidized })=1-\lambda_{2}=\frac{1-\alpha}{1-\alpha \cdot p} .
$$

The ratio $\frac{\lambda_{3}}{\lambda_{4}}$ must equal the ratio of low quality to high quality projects $\frac{1-p}{p}$. Therefore

$$
\begin{aligned}
\lambda_{3} & =(1-p) \cdot \frac{1-\alpha}{1-\alpha \cdot p} \\
\lambda_{4} & =p \cdot \frac{1-\alpha}{1-\alpha \cdot p} .
\end{aligned}
$$

If a subsidy is observed, banks can be sure that the project is of high risk type, thus $\mu=1$. Banks will therefore decide to give a loan when no subsidy is observed if

$$
\left.\lambda_{2} \cdot(\tilde{A}-x)+\lambda_{3} \cdot(\tilde{B}-x)\right)+\lambda_{4} \cdot(\tilde{B}+x)>0,
$$

and give a loan when a subsidy is observed if

$$
\tilde{C}+x>0 .
$$

a) If both equations hold, the agency has no incentive to deviate for high risk types since

$$
-S+I_{H}(S)>I_{H}(P),
$$

and no incentive to deviate for low risk types since

$$
I_{L}(P)>-S+I_{L}(S+P) .
$$

b) If both equations do not hold, the agency has no incentive to deviate since for the high risk types the payoff is

$$
-S+I_{H}(S)>0,
$$

and for the low risk types the payoff is

$$
0>-S+I_{L}(S) .
$$


c) If (4.5) does not hold and (4.6) holds, the agency's payoff is 0 for low risk type projects and it therefore has no incentive to deviate if $-S+I_{L}(S+P)<0$. For high risk type projects the agency never has an incentive to deviate since $-S+I_{H}(S+P)>0$.

d) If 4.6 does not hold and 4.5 holds, the agency's payoff for high risk projects is $-S+I_{H}(S)$ and it has no incentive to deviate for high risk projects if $I_{H}(P)<$ $-S+I_{H}(S)$. For low risk type projects the agency never has an incentive to deviate since $I_{L}(P)>-S+I_{L}(S)$.

Thus, if one of the four conditions holds, there is an equilibrium where high risk projects are subsidized and low risk projects are not.

Proof of Proposition 6. a) If the agency is always granting a subsidy, it is still possible to be in the no subsidy information set in equilibrium because of the automatically rejected projects. Therefore, banks are not free to choose their beliefs $\lambda_{i}$. The nodes belonging to $\lambda_{1}$ and $\lambda_{4}$ are not reached in equilibrium, therefore $\lambda_{1}=\lambda_{4}=0$. Nodes belonging to $\lambda_{2}$ and $\lambda_{3}$ are reached in equilibrium with a priori probabilities for high and low risk projects. Thus, $\lambda_{2}=\alpha, \lambda_{3}=1-\alpha$. If a subsidy is granted, the belief is calculated as $\mu=\frac{p \alpha}{p}=\alpha$. The rest of the proof works similar to the previous pooling equilibrium. Banks decide to give loans when a subsidy is observed if

$$
\alpha \cdot(\tilde{C}+x)+(1-\alpha)(\tilde{D}+x)>0,
$$

and when no subsidy is observed if

$$
\alpha \cdot(\tilde{A}-x)+(1-\alpha)(\tilde{B}-x)>0 .
$$

If 4.7) holds, there is no incentive to deviate for the high risk types since $-S+$ $I_{H}(S+P)>\max \left\{I_{H}(P), 0\right\}=I_{H}(P)$.

If 4.7) and 4.8 hold, there is an incentive to deviate for the low risk types since $-S+I_{L}(S+P)<I_{L}(P)$.

If 4.7 holds and (4.8) does not hold, there is an incentive to deviate for low risk types if $-S+I_{L}(S+P)<0$. There is no incentive to deviate for the high risk types since $\left.-S+I_{H}(S+P)>0\right\}$.

If 4.7) does not hold, there is an incentive to deviate for the low risk types since $-S+I_{L}(S)<\min \left\{I_{L}(P), 0\right\}=0$.

Thus, there is an equilibrium where the agency is pooling on $\mathrm{S}$ if $\alpha \cdot(\tilde{C}+x)+(1-$ $\alpha)(\tilde{D}+x)>0, \alpha \cdot(\tilde{A}-x)+(1-\alpha)(\tilde{B}-x)<0$ and $-S+I_{L}(S+P)>0$. In this equilibrium the agency always grants a subsidy, banks give no loans if no subsidy is observed and give loans if a subsidy is observed. Banks' beliefs are $\lambda=\mu=\alpha$.

b) This proof exactly works as the proof for proposition 3 b). As banks cannot differentiate between low and high quality projects, the situation if no subsidy is observed 
is the same. For the argumentation off the equilibrium path, i.e., when a subsidy is observed, only banks' payoffs have to be adjusted.

\section{References}

[1] Bhattacharya, S. and J.R. Ritter (1983): Innovation and Communication: Signalling with Partial Disclosure, Review of Economic Studies, 50, pp. 331-346.

[2] Beise, M. and H. Stahl (1999): Public research and industrial innovations in Germany, Research Policy, 28, pp. 397-422.

[3] BMBF (1993): Bundesbericht Forschung, Bundesministerium für Bildung und Forschung, Bonn.

[4] Czarnitzki, D. and K. Hussinger (2004): The Link between R\&D Subsidies, R\&D Spending and Technological Performance, ZEW, Discussion Paper No. 04-56.

[5] Czarnitzki, D. and A. A. Toole (2006): Business R\&D and the interplay of R\&D subsidies and market uncertainty, ZEW, Discussion Paper No. 05-55.

[6] Da Rin, M., G. Nicodano and A. Sembenelli (2006): Public policy and the creation of active venture capital markets, Journal of Public Economics, 90, pp. 1699-1723.

[7] David, P.A., B.H. Hall and A.A. Toole (2000): Is public R\&D a complement or substitute for private R\&D? A review of econometric evidence, Research Policy, 29, pp. 497-529.

[8] Funk, M.(2002): Basic Research and International Spillovers, International Review of Applied Economics, 16, pp. 217-226.

[9] Hall, B.(2002): The Financing of Research and Development, Oxford Review of Economic Policy, 18, pp. 35-51.

[10] Hinloopen, J. (1997): Subsidizing Cooperative and Noncooperative R\&D in Duopoly with Spillovers, Journal of Economics, 66, pp. 151-175.

[11] Hinloopen, J. (2000): More on Subsidizing Cooperative and Noncooperative R\&D in Duopoly with Spillovers, Journal of Economics, 72, pp. 295-308.

[12] Holmstrom, B. and J. Tirole (1997): Financial intermediation, loanable funds, and the real sector, Quarterly Journal of Economics, 62, pp. 663-691.

[13] IW (2008): Deutschland in Zahlen 2008, Institut der deutschen Wirtschaft, Köln.

[14] Kamien, M.I., E. Muller and I.Zang (1992): Research Joint Ventures and R\&D Carttels, American Economic Review, 82, pp. 1293-1306. 
[15] Klette, T.J., J. Møen and Z. Griliches (2000): Do Subsidies to commercial R\&D reduce market failures? Microeconometric evaluation studies, Research Policy, 29, pp. 471-495.

[16] Lerner, J.(1999): The Government as Venture Capitalist: The Long-Run Impact of the SBIR Program, Journal of Business, 72, pp. 285-318.

[17] Lichtenberg, F.R. (1984): The Relationship between Federal Contract R\&D and Company R\&D, American Economic Review, 74, pp. 73-78.

[18] Lichtenberg, F.R. (1987): The Effect of Government Funding on Private Industrial Research and Development: A Re-Assessment, The Journal of Industrial Economics, 36, pp. 97-104.

[19] Meuleman, M. and De Maeseneire, W. (2008): Do R\&D Subsidies affect SMEs' access to external Financing?, Vlerick Leuven Gent Working Paper Series 2008/12.

[20] NGA (2008): State Strategies to Promote Angel Investment for Economic Growth, National Governors Association Center for Best Practices, Issue Brief, download from http://www.nga.org/Files/pdf/0802ANGELINVESTMENT.PDF.

[21] Repullo, R. and J. Suarez (2000): Entrepreneurial moral hazard and bank monitoring: A model of the credit channel, European Economic Review, 44, pp. 1931-1950.

[22] Romano, R.E. (1989): Aspects of R\&D Subsidization, Quarterly Journal of Economics, 104, pp. 863-873.

[23] Spence, M. (1984): Cost Reduction, Competition, and Industry Performance, Econometrtica, 52, pp. 101-121.

[24] Takolo, T. and T. Tanayama (2008): Adverse Selection and Financing of Innovation: Is there a need for R\&D Subsidies? Bank of Finland Research Discussion Paper $19 / 2008$.

[25] Ueda, M. (2004): Banks versus Venture Capital: Project Evaluation, Screening, and Expropriation, Journal of Finance, 59, pp. 601-621. 